ISSN 2236-0859

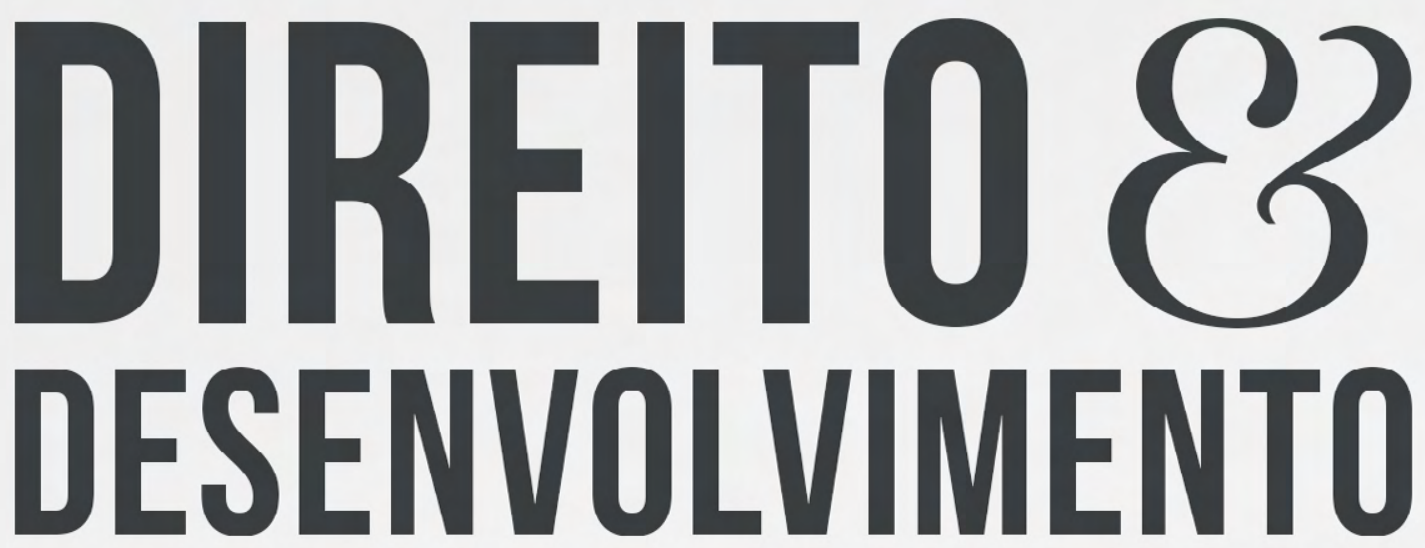

REVISTA DO PROGRAMA DE PÓS-GRADUAÇÃO EM DIREITO MESTRADO EM DIREITO E DESENVOLVIMENTO SUSTENTÁVEL

\title{
ODIREITO À SEGURANCA PESSOAL DAS POPULAÇÕES FRONTEIRICSAS DO MERCOSUL SOB A PERSPECTIVA DO DIREITO INTERNACIONAL DOS DIREITOS HUMANOS
}

ELIO RICARDO CHADID DA SILVA VLADMIR OLIVEIRA DA SILVEIRA 


\title{
O DIREITO À SEGURANÇA PESSOAL DAS POPULAÇÕES FRONTEIRIÇAS DO MERCOSUL SOB A PERSPECTIVA DO DIREITO INTERNACIONAL DOS DIREITOS HUMANOS
}

\author{
THE RIGHT TO PERSONAL SECURITY OF MERCOSUR \\ BORDER POPULATIONS UNDER THE PERSPECTIVE OF THE \\ INTERNATIONAL HUMAN RIGHTS LAW
}

Recebido: 30/07/2018

Aprovado: 19/09/2018

Elio Ricardo Chadid da Silva*

Vladmir Oliveira da Silveira**

\begin{abstract}
RESUMO: Na presente pesquisa aborda-se a problemática da criminalidade transnacional nas fronteiras do Mercosul sob a perspectiva do Direito Internacional dos Direitos Humanos. Nesse sentido, analisa-se como isso afeta os indivíduos das referidas regiões, bem como se o Direito à Segurança Pessoal é salvaguardado pelos atores internacionais. Discute-se se a efetividade dos referidos direitos humanos em questão pode ser alcançada por paradigmas fundados na acepção clássica da Teoria Geral do Estado, em que a soberania nacional é exercida de forma hermética, ou se um novo referencial, baseado na cooperação internacional, seria mais adequado à resolução da problemática proposta. Para tanto, traça-se um panorama da violência decorrente da atividade criminosa nas fronteiras e como isso impacta o Direito ao Desenvolvimento de suas vítimas naquelas regiões e, ainda, se examina a efetividade da forma tradicional de combate à criminalidade. Utiliza-se, na pesquisa, o método hipotético-dedutivo, e as técnicas descritiva, documental e bibliográfica.
\end{abstract}

Palavras-chave: Direito internacional dos direitos humanos. Mercosul. Direito à segurança pessoal. Direito ao desenvolvimento. Fronteiras.

\begin{abstract}
This research deals with the problem of transnational crime on the borders of Mercosur under the perspective of International Human Rights Law. In this sense, it is analyzed how this affects the individuals of those regions, as well as if the Right to Personal Security is safeguarded by the international actors. It is discussed whether the effectiveness of these human rights in question can be achieved by paradigms based on the classical General State Theory, in which national sovereignty is exercised hermetically, or whether a new referential based on international cooperation would be solution to the proposed problem. In order to do so, a picture of the violence resulting from the criminal activity at the borders is presented and how this impacts the Right to Development of its victims in those regions, and also examines the efficiency of the traditional way of combating crime. The hypothetical-deductive method and the descriptive, documentary and bibliographic techniques are used in the research.
\end{abstract}

Keywords: International human rights law. Mercosur. Right to personal security. Right to development. borders.

\footnotetext{
* Mestrando em Direito, com área de concentração em Direitos Humanos (UFMS). Pós-Graduado (Lato Sensu) em Direito Penal e Processual Penal, pela Faculdade Damásio de Jesus - SP (2015) e em Direito Tributário, pelo Instituto LFG / Universidade ANHANGUERA-UNIDERP - MS (2010). Analista Judiciário (na função de Assessor de Desembargador) no Tribunal de Justiça de Mato Grosso do Sul. Experiência na área de Direito, com ênfase em Direito Público. E-mail: eliochadid@gmail.com

** Pós-doutor em Direito pela Universidade Federal de Santa Catarina - UFSC (2009). Doutor em Direito pela Pontifícia Universidade Católica de São Paulo (2006). Mestre em Direito pela Pontifícia Universidade Católica de São Paulo (2003), Graduação em Direito em (1997) e Graduação em Relações Internacionais pela mesma Universidade (200o). Professor Titular em Direitos Humanos da Universidade Federal de Mato Grosso do Sul. Foi Coordenador do Programa de Mestrado em Direito da UNINOVE (2011-2016). É Professor da Pontifícia Universidade Católica de São Paulo - PUC/SP. E-mail: vladmir.silveira@ufms.br.
} 


\section{INTRODUÇÃO}

A atual realidade mundial, moldada pelo processo de globalização iniciado no final do século XX, traz consequências não vivenciadas antes e, portanto, não pensadas pela sociedade pós-moderna. Uma dessas consequências é a mudança do conceito de fronteiras, que anteriormente se configuravam como limites entre os territórios e proteção de uma determinada nação, ou seja, serviam de delimitadoras do exercício da soberania de um determinado Estado. Atualmente, porém, se mostram como sendo nada mais do que simples marcos formais, dado o crescente fluxo de pessoas e bens entre os espaços geográficos de cada país, propiciado, dentre outros fatores, pelo fenômeno da economia transnacional e dos avanços tecnológicos, experimentados pelo mundo no alvorecer do século XXI.

Em razão do processo globalizador há um verdadeiro enfraquecimento da função de proteção e vigilância das fronteiras, mormente as existentes nos países do Mercosul. Notese que, se por um lado, é até necessário para a integração pacífica entre os povos, por outro, acaba propiciando o aumento da violência nessas regiões, pelo incremento de atividades das organizações criminosas transnacionais, as quais se modernizaram e se internacionalizaram, fator que pode comprometer o exercício do Direito ao Desenvolvimento das populações que habitam as regiões estudadas.

Com efeito, pela atuação contundente das mencionadas organizações criminosas nas fronteiras, as pessoas que habitam essas regiões ficam desprotegidas e, desse modo, descobertas da proteção relativa ao direito à segurança pessoal, que deveria lhes salvaguardar de todo tipo de atentado a suas vidas e integridade, seja física, moral e/ou psíquica, bem como proporcionar-lhes o desenvolvimento pleno e saudável.

É a partir da problemática da violência nas fronteiras, contrastando com a garantia do direito humano à segurança pessoal, que se analisará as razões pelas quais as regiões fronteiriças se transformaram em palco de atuação de organizações criminosas internacionais, bem como se o modelo de enfrentamento a tal situação é eficiente ou não. A pesquisa terá, como objetivos, traçar um breve panorama da violência decorrente da atividade criminosa nas regiões de fronteiras do Mercosul, e verificar se o atual panorama indica se a segurança pessoal está sendo garantida em tais regiões, bem como se oferece condições de desenvolvimento dos indivíduos que lá habitam.

A pesquisa se justifica na medida em que se analisará a necessidade de proteção às pessoas nas regiões limítrofes dos países do Mercosul, uma vez que, se é objetivo do bloco buscar a integração plena entre seus membros (como, inclusive, consta no artigo $4^{\circ}$, parágrafo único, da Constituição do Brasil, quando propugna a "formação de uma comunidade latinoamericana de nações”), é dever de todos eles, via cooperação internacional, oferecer ao menos segurança pessoal a seus cidadãos, principalmente para aqueles que habitam as faixas de fronteira, com o que se poderá propiciar o tão desejado desenvolvimento interestatal e, ainda, a integração entre as nações sul-americanas.

Para atingir seu desiderato, o trabalho se iniciará com uma abordagem sobre o direito à segurança pessoal no âmbito do Direito Internacional dos Direitos Humanos, especialmente como consta na Declaração Universal dos Direitos Humanos. Em seguida, se analisará o conteúdo jurídico do direito à segurança pessoal no âmbito da OEA, do Mercosul e dos países componentes deste último bloco. Na sequência, contextualizará a situação do direito à segurança pessoal nas faixas de fronteira do Brasil no Mercosul, assim como as consequências de tal contexto em relação ao Direito ao Desenvolvimento das pessoas nas mencionadas regiões. Por fim, se ponderará acerca da cooperação regional entre os países como possível forma de efetivação do direito à segurança pessoal nas fronteiras sul-americanas. 
A pesquisa se valerá do método hipotético-dedutivo, e das técnicas descritiva, documental e bibliográfica.

\section{O DIREITO À SEGURANÇA PESSOAL NO DIREITO INTERNACIONAL}

Em diversos momentos históricos, seja qual for o referencial dogmático levado em consideração (o religioso, o positivista, o jusnaturalista, o pós-moderno ou o relativo à teoria do risco), a vida é, na quase totalidade das vezes, colocada como o centro e maior preocupação dos juristas.

É bem verdade que, em alguns países ou situações, o valor da vida é relativizado, como ocorre em nações que ainda insistem em admitir a aplicação da pena de morte e outras práticas que fragilizam esse direito essencialmente civilizatório.

Contudo, num contexto jurídico mundial, o direito à vida é, seguramente, o direito angular de todos os direitos a partir de determinados momentos históricos, sendo basilar também no âmbito do Direito Internacional dos Direitos Humanos.

Obviamente que seria inócuo falar-se em direito à vida sem prover meios para que ele seja preservado de maneira digna, sem abalos externos. É nesse contexto que surge, como garantidor do direito à vida, o direito à segurança pessoal, que deve, como ocorre com o direito antes mencionado, ser objeto de salvaguarda tanto pelos Estados quanto pelas Organizações Internacionais.

A preocupação com a salvaguarda (no sentido de proteção) do direito à vida é explicitada no artigo III, da Declaração Universal dos Direitos Humanos, o qual estabelece que "todo ser humano tem direito à vida, à liberdade e à segurança pessoal" (ONU, 1948). Nesse sentido, o ordenamento jurídico internacional busca não somente assegurar o direito à vida propriamente dito, mas também colocar a salvo os indivíduos de toda e qualquer violação à integridade física, moral e psíquica daqueles, ou seja, protegê-los de toda forma de violência que pode ser perpetrada contra o ser humano. É nessa perspectiva que se desenvolve o direito à segurança pessoal, tanto no âmbito da Organização das Nações Unidas (ONU), como nas esferas regionais das Organizações Internacionais, como é o caso da Organização dos Estados Americanos (OEA), em especial a sua Comissão Interamericana de Direitos Humanos (CIDH), e também do Mercado Comum do Sul (Mercosul), o que torna o tema objeto de estudo do Direito Internacional dos Direitos Humanos.

\subsection{O Conteúdo Jurídico do Direito à Segurança Pessoal na Organização dos Estados Americanos (OEA)}

Primeiramente, convém esclarecer que a Organização dos Estados Americanos (OEA) utiliza o termo "segurança cidadã" como terminologia padrão para tratar a problemática em epígrafe (em lugar das tradicionais terminologias "segurança pública”, "segurança humana", "segurança interior" ou "ordem pública"), tendo em vista que referido termo invoca uma abordagem dos problemas da criminalidade e da violência a partir de uma perspectiva de direitos humanos. Ainda segundo a OEA, o conceito em questão deriva de um enfoque na construção de maiores níveis de cidadania democrática, colocando a pessoa humana como objetivo central das políticas, de forma diversa da visão ultrapassada de segurança do Estado ou de ordem política. 
A preocupação com a garantia do direito à segurança cidadã na OEA se intensifica a partir do ano de 2008, quando se realizou, na Cidade do México, a "Primeira Reunião de Ministros em Matéria de Segurança Pública das Américas”, ocasião em que as autoridades reunidas firmaram o "Compromisso pela Segurança Pública nas Américas". No compromisso restou estabelecido, dentre outras prioridades: a) o fomento e o fortalecimento de políticas de Estado em matéria de segurança pública de longo prazo, com respeito aos direitos humanos; b) o fortalecimento da capacidade dos Estados para promover a segurança cidadã, com resposta eficaz à insegurança, delinquência e violência; c) o fortalecimento da segurança fronteiriça, conforme os ordenamentos jurídicos e administrativos aplicáveis aos Estados Membros, como forma de prevenir a delinquência e a violência, sempre facilitando o fluxo legítimo de pessoas e bens; e d) considerar iniciativas de cooperação para ampliar o conhecimento sobre os diversos aspectos e o impacto da criminalidade nos Estados Membros, com vistas ao fortalecimento das estruturas de políticas de segurança pública (OEA, 2008).

Posteriormente, no ano de 2010, a Comissão Interamericana de Direitos Humanos (CIDH), que é uma das entidades do sistema interamericano de proteção e promoção dos direitos humanos nas Américas, emitiu o "Relatório sobre Segurança Cidadã e Direitos Humanos", documento que traça um panorama acerca da temática no continente americano, nos 25 (vinte e cinco) anos anteriores à elaboração do estudo, bem como estabelece recomendações a serem observadas pelos países membros da OEA. Dentre essas recomendações destacamse: a) assumir o cumprimento de suas obrigações internacionais de proteção e garantia dos direitos humanos em relação com a segurança cidadã a partir da elaboração e implementação de políticas públicas integrais que desenvolvam, de maneira simultânea, ações específicas e planos estratégicos sob a ótica operacional, normativa e preventiva; b) garantir a execução por parte das forças policiais de todas as atividades operacionais que permitam a implementação das funções de prevenção, dissuasão e repressão legítima de atos violentos ou criminosos, como parte da obrigação do Estado de proteger e garantir os direitos humanos comprometidos diretamente na política de segurança cidadã; e c) gerar as capacidades estatais necessárias para identificar e punir os autores de crimes contra a vida (CIDH, 2010).

Dessa forma, é possível perceber-se que a preocupação com a segurança cidadã é algo recorrente no âmbito dos organismos internacionais das Américas, sendo constatável que tais organismos, responsáveis pela promoção e proteção dos direitos humanos, além de estudar e mapear a criminalidade no continente americano, propõem uma série de recomendações a serem seguidas por seus países membros, como forma de, senão debelar, ao menos minimizar os efeitos maléficos da violência perpetrada contra as populações do continente, mormente os mais vulneráveis, como se pode concluir a partir de trecho do Relatório produzido pela CIDH:

\footnotetext{
Ainda, a CIDH recomenda aos Estados membros que garantam os parâmetros especiais de proteção requeridos por aquelas pessoas, ou grupos de pessoas, em especial situação de vulnerabilidade frente à criminalidade, como as crianças e adolescentes, as mulheres, a população indígena e afrodescendentes e as pessoas migrantes e seus familiares, sem prejuízo de que as obrigações de proteção e garantia dos direitos humanos comprometidos na política de segurança cidadã assumidas pelos Estados Membros incluam a todas as pessoas sob sua jurisdição. (CIDH, Relatório sobre Segurança Cidadã e Direitos Humanos, 2010, p. 10).
}

Realizadas as explanações acerca de como o tema é versado no âmbito regional das Américas, convém trazer o tratamento da questão na América do Sul, mais especificamente no âmbito sub-regional do Mercado Comum do Sul (Mercosul), que possui cinco países membros efetivos (Brasil, Paraguai, Uruguai, Argentina e Venezuela), e tem os demais países sul-americanos como membros associados do bloco. 


\subsection{Conteúdo Jurídico do Direito à Segurança Pessoal no âmbito do Mercosul}

No âmbito do Mercosul, seguindo as diretrizes e terminologias adotadas pela OEA, o Instituto de Políticas Públicas em Direitos Humanos do Mercosul (IPPDH) e o Escritório Regional para América do Sul, repartição do Alto Comissariado das Nações Unidas para os Direitos Humanos (ACNUDH), lançaram, no ano de 2012, o documento "Produção e gestão da informação e do conhecimento no campo da segurança cidadã: os casos da Argentina, Brasil, Paraguai e Uruguai”. Conforme esclareceram as pesquisadoras responsáveis, "o estudo propôs mapear, identificar e descrever os tipos de sistemas de informação existentes nas áreas de Justiça, Interior e/ou Segurança nos Estados parte do Mercosul em matéria de violência e criminalidade". Destacou-se, ainda, que a gestão adequada e o conhecimento no campo da segurança cidadã é condição essencial para alcançar uma governabilidade democrática da segurança pública que tenha como centro os direitos humanos (IPPDH; ACNUDH, 2012).

Apesar das diretrizes traçadas pelo estudo em epígrafe, e de existirem algumas outras poucas iniciativas sobre o tema, é forçoso concluir-se que, no Mercosul, a abordagem acerca das questões relacionadas à segurança cidadã ainda é incipiente, se tomar-se como base o fato de que o bloco é bem menor do que a OEA, o que, ao menos em tese, e justamente pela dimensão reduzida, deveria facilitar a aplicação das recomendações, tanto da OEA quanto daquelas produzidas no próprio bloco sul-americano, como forma de efetivar as diretrizes da segurança pessoal na América do Sul.

Convém pontuar, também, que a pouca efetividade das medidas tendentes à minoração dos efeitos das práticas criminosas transnacionais nos países do Mercosul, como forma de proteção a seus concidadãos (oriundas dos debates na OEA e no próprio bloco sub-regional), provavelmente é fruto das mesmas dificuldades encontradas para a efetiva formação do próprio bloco latino-americano. Se o bloco não consegue, por diversos fatores, consolidar todas as suas metas iniciais, a exemplo das questões de livre comércio e da diminuição (ou eliminação) da lista de exceções da TEC (Tarifa Externa Comum), é evidente que também terá dificuldades de implementar, como bloco sub-regional, providências efetivas no sentido de oferecer segurança às pessoas que habitam as nações do bloco, seja nas regiões de fronteira, seja em qualquer outro ponto da América do Sul.

\section{O CONTEXTO DO DIREITO À SEGURANÇA PESSOAL NAS FRONTEIRAS DO MERCOSUL}

Conforme os relatórios sobre segurança cidadã elaborados tanto no âmbito da CIDH quanto no do Mercosul, a violência contra os indivíduos que habitam o continente americano, decorrente da prática de crimes que atentam contra a vida e integridades física e psíquica das pessoas, é preocupante e cresce a cada ano. Em relação às fronteiras do Mercosul, o quadro em comento se deve, em grande parte, à atuação de grandes organizações criminosas transnacionais, responsáveis pelo cometimento de vários delitos, como homicídios ligados a atividades de narcotráfico, tráfico de armas e contrabando, e, em contraposição, à escassez ou falta de efetividade de medidas de prevenção e repressão a esse tipo de atividades ilícitas, que põem em risco os habitantes dessas regiões. 


\subsection{A fronteira como elemento facilitador da prática de crimes}

Partindo-se do senso comum, o conceito de fronteira passa pela ideia de limite, de barreira, seja ela física ou jurídica. Com a evolução das organizações sociais humanas, que se politizaram ao longo da história, a fronteira passou a ter outras conotações, denominações e diferenciações terminológicas.

Assim, é comum a distinção entre fronteiras e limites, por exemplo, sendo que o termo 'fronteira' refere-se a uma região ou faixa, enquanto o termo 'limite' está ligado a uma concepção imaginária". Ainda no mesmo sentido, "A fronteira é mais abrangente e refere-se a uma região ou faixa do território situado em torno dos limites internacionais. Limite é uma concepção precisa, linear e perfeitamente definida no terreno" (LARA ALEGRE, 2011, p. 19).

Seja um ou outro o termo adotado, o fato é que, por conta do fenômeno da globalização, as fronteiras passaram por um processo de ressignificação. E isso porque o avanço desse fenômeno, ocorrido principalmente nas últimas décadas do século XX e começo do atual, principalmente pelas conquistas tecnológicas vivenciadas na pós-modernidade, acabou por redesenhar a maneira como as pessoas da região de fronteira se inter-relacionam. Essa é a constatação dos estudiosos que pesquisam sobre a questão:

\footnotetext{
Diante desse aumento vertiginoso do fluxo de pessoas, inegavelmente a porosidade das fronteiras políticas se intensificou. Com a maior mobilidade humana e o consequente maior contato entre os povos, diversas questões delicadas podem ser postas em observação. Uma delas é o aumento do contato entre culturas verificado pelo maior fluxo de mobilidade humana que a globalização acarretou. (AGUILERA URQUIZA; RIBEIRO, 2017, p. 249)
}

O aumento de contato entre pessoas e culturas na fronteira, por conta da porosidade daquela região gerada pela globalização (na expressão utilizada pelos autores nominados), propiciou, também, a facilitação de um maior trânsito das organizações criminosas internacionais entre as fronteiras dos países do Mercosul, possivelmente pela baixa eficácia de controle ou fiscalização por autoridades de quaisquer dos países fronteiriços, tendentes a inibir a prática de crimes transnacionais.

Com efeito, a prática de crimes transnacionais certamente foi muito favorecida com o aumento e facilitação do fluxo de pessoas e bens entre os países, pois, se com as fronteiras relativamente vigiadas de antigamente, o crime organizado já era, de certa forma, "globalizado" (podendo mesmo ser chamado de precursor de um tipo de globalização negativa), a partir do processo em questão, com o afrouxamento das antigas barreiras (que é necessário e bemvindo para a integração das nações), a prática de crimes e a fuga de criminosos para os países vizinhos, lamentavelmente, se tornou muito mais rotineira e fácil de ser observada.

\subsection{Análise da efetividade da forma tradicional de combate aos crimes transnacionais}

Analisando-se vários excertos sobre a temática de prática de crimes transfronteiriços, há praticamente um consenso de que é primordial que ocorra a conjugação das forças policiais, investigativas e acusatórias de todos os atores responsáveis pela gestão da segurança cidadã, para o enfrentamento eficaz do problema.

Todavia, a forma tradicional de combate à criminalidade nas regiões de fronteira, na qual cada país enfrenta o problema utilizando-se somente de seus próprios arcabouços 
jurídicos e forças de segurança, de forma estanque e sem integração efetiva e eficaz com os países vizinhos, acaba por proporcionar o incremento das atividades criminosas, haja vista que, na grande maioria das vezes, basta que o criminoso atravesse a linha de fronteira de volta para seu país de origem, para que se torne muito difícil puni-lo, vez que a persecução criminal pelo país onde o crime foi cometido esbarraria, na hipótese, na soberania da nação contígua, que "protege" seu cidadão da incidência das leis do país vizinho, além é claro da garantia da não extradição de nacional.

Para se ter uma ideia da dimensão do problema de fiscalização e controle fronteiriços, convém trazer a lume a situação do Brasil, o maior país membro do Mercosul. As fronteiras do Brasil com 10 (dez) países sul-americanos se estendem por nada menos do que aproximadamente 17.00o quilômetros, passando por um total de 11 (onze) Estados-membros e 588 (quinhentos e oitenta e oito) municípios brasileiros. Com o intuito de conter o avanço da criminalidade transnacional, o Brasil conta com algumas iniciativas, entabuladas, em conjunto ou separadamente, pelos Ministérios da Defesa, da Justiça e da Segurança Pública do país, destacando-se as seguintes: a) o SISFRON (Sistema Integrado de Monitoramento de Fronteiras Terrestres), do Ministério da Defesa; b) o SIVAM (Sistema de Vigilância da Amazônia), do Ministério da Defesa (Comando da Aeronáutica); c) a ENAFRON (Estratégia Nacional de Segurança Pública nas Fronteiras), dos Ministérios da Defesa, Justiça e Segurança Pública, dentre outras medidas.

Todos esses e outros sistemas e estratégias vêm sendo implantados e modificados desde o começo dos anos 1990, mas são realizados, em sua maioria, somente pelo governo brasileiro, de forma exclusiva. É verdade que, em uma ou outra ocasião, ocorrem operações conjuntas com um ou outro país vizinho, mas essas são apenas pontuais e, geralmente, não envolvem todos os países do bloco sul-americano de forma coordenada. Note-se que essa é a forma tradicional de vigilância e combate à criminalidade transnacional, do ponto de vista do Brasil, que, segundo os informes e estatísticas oficiais, não é suficiente para a resolução do problema.

Observa-se, ainda, que o problema fica ainda mais complexo quando se verifica que a persecução criminal, em relação a seus nacionais e aos crimes cometidos nos próprios territórios, é muito fraca, ineficaz, dentro de cada país do Mercosul, em razão da constatação de que existe um grande número de crimes nacionais não solucionados e não punidos. Assim, se os países membros do bloco não conseguem combater, eficazmente, nem os crimes cometidos exclusivamente em seus territórios, envolvendo seus próprios cidadãos, é evidente que o combate aos crimes transnacionais se torna muito fraco e inexpressivo, se for levado a cabo por cada país de forma isolada. Tal conclusão é praticamente uníssona na comunidade acadêmica:

\footnotetext{
Ao operar no plano internacional, as associações criminosas transnacionais põem por terra o conceito de soberania Estatal, desrespeitando todo e qualquer limite territorial ou político, sempre que necessário para o sucesso de suas atividades. O crime organizado transnacional é uma ameaça aos Estados e à própria sociedade internacional, não sendo possível a qualquer Estado combater a atividade desses grupos isoladamente. (LESSA, 2017, p.48)
}

Assim, os fatores alinhavados nos parágrafos anteriores geram, em relação aos agentes criminosos internacionais, o que se denomina de certeza da impunidade, do que decorre, mais uma vez, a conclusão de que a forma usual de combate aos crimes transnacionais encontra-se totalmente defasada. 


\title{
3.3 A violência nas fronteiras e os obstáculos ao exercício do Direito ao Desenvolvimento
}

Antes de tratar do impacto quea violência fronteiriça causa ao direito ao desenvolvimento, é salutar uma breve explanação acerca do tema. O direito ao desenvolvimento é direito humano doutrinariamente classificado como de terceira dimensão, e é mencionado pela primeira vez, de forma expressa, na Carta das Nações Unidas, de 1945. Depois disso, foi objeto de outros documentos, merecendo destaque a "Declaração sobre o Direito ao Desenvolvimento", de 1986, que, em seu artigo $1^{\circ}$, $§ 1^{\circ}$, dispõe: "o direito ao desenvolvimento é um direito inalienável, em virtude do qual toda pessoa e todos os povos estão habilitados a participar do desenvolvimento econômico, social, cultural e político, para ele contribuir e dele desfrutar". Consta, ainda, na Declaração, que pelo desenvolvimento deve-se propiciar ambiente para que todos os direitos humanos e liberdades públicas possam ser realizados de forma plena.

A importância da Declaração de 1986 se deve ao fato de o documento retirar do Direito ao Desenvolvimento o antigo paradigma de direito referente aos Estados e colocar o ser humano como titular de tal direito, cotejando-o com outros direitos humanos, numa perspectiva de necessidade de aprimoramento de direitos nacionais em conjunto com a cooperação internacional, como alertam os pesquisadores:

\footnotetext{
Em meio a esse quadro de reestruturação do cenário internacional, o vetor políticoeconômico sempre apresentou um grande peso, especialmente no estabelecimento de normas de regulamentação das relações econômicas e financeiras internacionais. Considerando essa questão, o grande marco da Declaração de 1986, que reconhece o direito humano ao desenvolvimento, é o de aproximar esse direito com os conceitos de justiça social, democracia, meio ambiente, política pública, direitos humanos e cooperação internacional.
}

\begin{abstract}
Nesse sentido, cumpre destacar as três dimensões centrais que Allan Rosas (1995) apresenta sobre o conteúdo do direito ao desenvolvimento, a partir da Declaração de 1986, em que, em primeiro lugar endossa a importância da participação, em segundo corrobora para a necessidade básica de justiça social, e em terceiro enfatiza a necessidade de adoção de programas e políticas nacionais e programas de cooperação internacional. (SÁTIRO; MARQUES; OLIVEIRA, 2016, p. 182).
\end{abstract}

É de bom alvitre esclarecer, também, que o direito ao desenvolvimento, além de se tratar de direito humano de terceira geração, é aglutinador de todos os demais Direitos Humanos, uma vez que, para que seja realizado em sua integralidade, é necessário que os direitos de outras dimensões, fundamentados no paradigma da dignidade da pessoa humana, também sejam efetivados.

Dessa forma, para que de fato haja desenvolvimento, é imprescindível garantir-se direitos de primeira dimensão, como o direito à vida e à liberdade; direitos de segunda geração, como os direitos sociais (saúde, educação, segurança, trabalho, etc.); além de outros direitos de terceira dimensão, como o direito ao meio ambiente equilibrado e à paz. Em outras palavras, o Direito ao Desenvolvimento acaba por condensar, em certa medida, o que se convencionou denominar de processo de "dinamogenesis" dos Direitos Humanos, segundo o qual a sociedade inicialmente reconhece o valor fundante dos direitos humanos, que é a dignidade da pessoa humana. A partir daí, "[..] reconhecido como valioso, este valor impulsiona o reconhecimento jurídico, conferindo orientação e conteúdos novos (liberdade, igualdade, solidariedade, etc.), que expandirão o conceito de dignidade da pessoa" (SILVEIRA; ROCASSOLANO, 2010, p.199). 
Feitas essas considerações acerca do desenvolvimento, é interessante ressaltar que é indubitável que o processo de globalização e, mais especificamente, o de integração dos povos latino-americanos, tende a impactar primeiramente os cidadãos que habitam as regiões de fronteiras. No contexto da pesquisa, de análise de salvaguarda do direito à segurança cidadã no Mercosul, seria lógico pensar que os governos dos países envolvidos na questão deveriam dar maior atenção aos habitantes das regiões fronteiriças, com maior suporte econômico, principalmente às pessoas de baixa renda que, por serem mais vulneráveis do ponto de vista social, costumam ser a parcela mais atingida pelos desmandos impostos pelo crime organizado internacional.

Todavia, parece que não é esse o cenário identificado no bloco sul-americano, se verificada, por exemplo, a situação da violência nas fronteiras das três regiões do Brasil (Norte, Centro-Oeste e Sul) que possuem Estados federados limítrofes com algum país sul-americano. A título de ilustração, pode-se mencionar o caso do Estado do Acre, que faz fronteira com a Bolívia e com o Peru, e que experimenta, desde o ano de 2015, uma escalada de violência sem precedentes, por conta da disputa travada entre facções criminosas que iniciaram uma verdadeira guerra, tendo como objetivo a apropriação das rotas internacionais do tráfico de drogas. Desde o ano de 2015 e até o ano de 2018 o número de homicídios no Estado saltou 150\% em relação a período imediatamente anterior, o que demonstra que o território estadual é o que mais teve um incremento desse tipo de crime no país, segundo dados estatísticos apurados pelo Observatório de Análise Criminal do Ministério Público do Estado do Acre.

Outro exemplo da situação periclitante da região de fronteiras é consta num estudo realizado pelo Instituto de Desenvolvimento Econômico e Social de Fronteiras (IDESF), denominado "Características das Sociedades de Fronteira", que analisa as condições sociais das chamadas "cidades gêmeas" entre dois países. Referido estudo teve como objeto diversos municípios brasileiros das três regiões localizados nas fronteiras do Mercosul, sendo que, ao analisar o número de homicídios por cem mil habitantes na cidade de Guaíra, Paraná, que é limítrofe ao Paraguai, a pesquisa constatou que tal índice, no ano de 2013, foi de 68,34/10omil, o que é alarmante para uma cidade com aproximadamente 30.000 habitantes, e, também, se comparado ao mesmo índice da Capital do Estado (Curitiba) naquele mesmo ano, que foi de 28,39/10omil. (IDESF, 2014)

Pode-se apontar, também, os números de estudo semelhante em relação a outra região do Brasil (Centro-Oeste), elaborado nas fronteiras do Estado de Mato Grosso do Sul com o Paraguai e a Bolívia, em 2016, que conclui que as cidades fronteiriças do referido Estado federado estão: a) entre as com renda per capta mais baixas do país; b) com baixa empregabilidade; c) com altos índices de evasão escolar ainda no ensino fundamental e; d) com números proporcionais de homicídios maiores do que os da cidade do Rio de Janeiro. (IDESF, 2016)

Todos os números mencionados dão conta de que o direito à segurança pessoal nas fronteiras sul-americanas não está sendo provido pelas autoridades públicas que deveriam por ele se responsabilizar, pois são titulares únicos do poder que lhes é atribuído pelo povo e, portanto, garantidoras da segurança cidadã que deve ser franqueada à população. Essa ausência do poder público das nações envolvidas traz consequências sociais diretas nos campos da educação, trabalho, segurança, dentre outros, o que, indubitavelmente, autoriza a concluir-se, por consequência, que o Direito Humano ao Desenvolvimento, que abarca todos os demais, não está sendo franqueado aos indivíduos que habitam tais regiões.

Convém frisar, também, que não são raras as vezes em que as populações fronteiriças, justamente pelo baixo ou nenhum suporte social e econômico por parte dos Estados envolvidos, se veem obrigadas a se submeterem às regras impostas pelos narcotraficantes, contrabandistas e traficantes de armas, sem contar os episódios em que os residentes dessas áreas são cooptados, 
de forma praticamente compulsória, pelas organizações criminosas para delas fazer parte (uma vez que não há oportunidades dignas de trabalho e estudo nessas áreas).

É de bom alvitre ressaltar, ainda, que o projétil do fuzil e o próprio armamento presentes nas comunidades dominadas pelo tráfico de drogas do Rio de Janeiro, ou o crack que é vendido e consumido à luz do dia nas cracolândias na cidade de São Paulo e em outras cidades brasileiras, são produtos que invariavelmente passam pelas fronteiras do Brasil com os países vizinhos, o que demonstra que as consequências sociais da violência nessas regiões não se limitam às linhas fronteiriças, mas também avançam para as demais partes dos países que as compõem, a exemplo do que ocorre nas grandes cidades acima mencionadas.

\section{COOPERAÇÃO REGIONAL COMO FATOR DE EFETIVIDADE DO DIREITO À SEGURANÇA PESSOAL NAS REGIÕES FRONTEIRIÇAS}

Existem diversos paradigmas que podem ser invocados para se tratar da questão envolvendo a efetividade do direito à segurança pessoal nas fronteiras, que vão desde a concepção clássica de Estado soberano, com todas as suas instituições políticas de internalização do direito, aos conceitos de Estado Cooperativo, que buscam propiciar e pavimentar uma maior interação e cooperação internacional, tanto no aspecto jurídico quanto em outros setores fundamentais. É de alguns desses paradigmas que cuidam os tópicos que seguem.

\subsection{A correlação entre o conceito clássico de Estado soberano e os entraves na efetivação do Direito à Segurança Pessoal}

A vasta região de fronteira existente entre os países do Mercosul acaba se tornando um facilitador da prática de crimes, e um dos fatores que contribui para isso, certamente, são os entraves que o conceito de Estado soberano, dado pela acepção clássica da Teoria Geral do Estado, criam para uma eventual atuação integrada dos países fronteiriços. Segundo tal teoria, o Estado é constituído por população, território e governo, sendo que esses três elementos, em conjunto, são tidos como formadores e justificadores da soberania nacional.

Nessa visão, a soberania do Estado não encontraria qualquer limite dentro do próprio Estado da qual emana. Seria um poder uno, não contrastável por qualquer outro ente político dentro de um mesmo país. Conforme essa visão minimalista, a soberania bastaria a si própria, e regularia as relações de poder dentro de uma determinada ordem jurídica nacional. $\mathrm{O}$ problema surge quando essa visão é tomada como parâmetro para se sobrepor às normas de direito internacional, quando, então, o direito nacional teria como optar pelo "reconhecimento" ou não das normas internacionais em relação a seu território e cidadãos. Kelsen aponta os percalços e o imbróglio de ordens jurídicas resultantes desse pensamento:

Essa é uma consequência inevitável da teoria do reconhecimento baseada na hipótese de primazia do Direito Nacional. A maioria dos expoentes desses pareceres, porém, não os desenvolve até as suas últimas consequências. Eles concebem o mundo do Direito como uma quantidade de ordens jurídicas nacionais isoladas, cada uma delas soberana e cada uma delas contendo o Direito internacional como parte. Por motivos já explicados, esse pluralismo jurídico é logicamente impossível. Com base nesse parecer, existiriam, incidentemente, tantas ordens jurídicas internacionais diferentes quanto há Estados ou ordens jurídicas nacionais. É, porém, logicamente possível que diferentes teóricos interpretem o mundo do Direito partindo da soberania de diferentes Estados. Cada teórico pode pressupor a soberania do seu próprio Estado, isto é, pode 
aceitar a hipótese da primazia da sua própria ordem jurídica nacional. Então, ele tem de considerar o Direito internacional que estabelece as relações com as ordens jurídicas dos outros Estados e essas ordens jurídicas nacionais como parte da ordem jurídica do seu próprio Estado, concebido como uma ordem jurídica universal. Isso significa que o quadro do mundo do Direito variaria de acordo com o Estado que fosse tomado como base da interpretação. Dentro de cada um desses sistemas, erigidos sobre a hipótese da primazia do Direito nacional, apenas um Estado é soberano, mas esse Estado nunca seria o mesmo sequer em dois desses sistemas (KELSEN, 200o, p.548).

Nesse contexto, o conceito de soberania, que também tem seu viés político, pode servir e base para ações dos defensores do nacionalismo exacerbado, que não raras vezes o utilizam em seus discursos políticos (e não jurídicos) inflamados, principalmente quando querem fazer valer alguma norma oriunda de seu país em detrimento de norma estrangeira, ou como tentativa de esquiva de normas de direito internacional. Dallari, utilizando-se de ponto de vista próprio, e também com auxílio dos argumentos de outros estudiosos, alerta para referida questão ao refletir sobre o conceito de soberania:

[...] Por isso mesmo, deu margem ao aparecimento de uma tão farta bibliografia e à formulação de uma tal multiplicidade de teorias que acabou sendo prejudicado, tornando-se cada vez menos preciso e dando margem a todas as distorções ditadas pela conveniência. Essas distorções têm sido uma consequência, sobretudo, da significação política do conceito, que se encontra na base de seu nascimento e que é inseparável dele, apesar de todo o esforço, relativamente bem-sucedido, para discipliná-lo juridicamente. Atualmente, porém, não obstante a imprecisão ou as controvérsias, a expressão soberania vem sendo largamente empregada na teoria e na prática, às vezes até mesmo para justificar as posições de duas partes opostas num conflito, cada uma alegando defender sua soberania. Daí a observação feita por Kaplan e Katzenbach, de que não há no Direito Internacional um termo mais embaraçoso que soberania, parecendo-lhes que o seu uso impreciso e indisciplinado talvez se deva ao fato de haver-se tornado um "símbolo altamente emocional", amplamente utilizado para conquistar simpatias em face das tendências nacionalistas que vêm marcando nossa época. (DALLARI, 2009, p.74).

Dentre essas diversas facetas da soberania, e sobre o pretexto de exercê-la, há ainda os casos (a maioria) em que os Estados conferem algumas prerrogativas àqueles seus denominados cidadãos, dentre as quais encontra-se a negativa de extradição de um cidadão nato, sendo que disso decorre, por exemplo, a impossibilidade de um outro país processar, julgar e cumprir a sentença condenatória em relação ao estrangeiro, ainda que este tenha cometido crimes no território dessa outra nação, sejam eles de natureza transnacional ou não.

Obviamente que não se olvida que o Código Penal Brasileiro, em seu artigo $7^{\circ}$, privilegia o princípio da extraterritorialidade da lei penal, segundo o qual a lei penal pode ser aplicada a brasileiros que tenham cometido delitos em território estrangeiro, ou a estrangeiros que tenham perpetrado determinadas práticas criminosas. Também não se desconhece a existência e vigência do Decreto Federal no 3.468, de 17 de maio de 200o, que promulga o Protocolo de Assistência Jurídica Mútua em Assuntos Penais entre os governos do Brasil, da Argentina, do Paraguai e do Uruguai, que visa a facilitação de notificações de atos processuais, localização ou identificação de pessoas, medidas acautelatórias sobre bens, dentre outras providências de cunho burocrático e administrativo.

Contudo, mesmo diante da vigência de tais medidas legislativas, na prática, os Estados costumam oferecer demasiada proteção a um nacional quando este é detido praticando um delito transnacional, sob a justificativa do exercício da soberania, conforme se conclui pela simples análise dos números e informes oficiais dos países do Mercosul acerca da questão. Essa 
mencionada proteção quase absoluta ao cidadão de determinado país acaba inviabilizando as tentativas de efetivação de punição, de forma legal e legítima, às pessoas que cometem crimes nas faixas de fronteiras ou imediações. Isso ocorre porque, no caso das fronteiras do Mercosul, basta atravessar uma rua ou um rio, logo após cometer qualquer crime (seja homicídio, tráfico de drogas, de armas, etc.), que o cidadão, natural do país vizinho, estará protegido pela legislação de sua própria nação, que geralmente não permite a extradição de um nacional e, muitas vezes, não pune ou pune inadequada e insuficientemente o delinquente. Tal fato gera, nos criminosos internacionais, a tão propalada certeza da impunidade.

\subsection{Aplicação dos preceitos de Cooperação Internacional à problemática do Direito à Segurança Pessoal nas fronteiras}

Antes de analisar-se os preceitos da Cooperação Internacional, convém esclarecer que, nada obstante o apontamento das mazelas da soberania vista de uma maneira quase absoluta, referida qualidade do Estado foi e é importante para o desenvolvimento dos conceitos modernos de Estado Constitucional, que possui enfoque social e que preza pela observância dos Direitos Humanos. Isso decorre do fato de a soberania nacional servir e ter servido como contraponto à tentativa de domínio hegemônico das políticas externas econômicas neoliberais que, principalmente em países subdesenvolvidos, potencializa o capitalismo de tal modo que os Direitos Humanos, muito embora façam parte do arcabouço jurídico formal de determinada doutrina, são negligenciados na prática. É o que adverte Paulo Bonavides, ao tratar das tentativas do mercado internacional globalizado de remover ou enfraquecer o conceito de soberania de algumas nações:

E tais diligências destrutivas da autodeterminação das Nações se fazem com muito empenho, porque a soberania nacional é óbice à soberania dos mercados.

\footnotetext{
De titularidade internacionalizada e invisível, esta nova e dissimulada soberania dos mercados executa o projeto recolonizador das gigantescas associações de capital, que ignoram por completo os direitos dos povos e das Nações periféricas a romper as cadeias do subdesenvolvimento e espancar as trevas da noite em que a globalização os mergulhou. (BONAVIDES, 2012, p.35).
}

Esclarecidos os aspectos positivos da soberania nacional (quando serve de freio à imposição da soberania dos mercados), e os aspectos negativos de tal qualidade do Estado (quando o faz se fechar para o direito internacional), faz-se necessário ponderar que, no que se refere à segurança cidadã, o clamor de determinados países pelo respeito à soberania nacional, quando se contrapõe às tentativas de assegurar-se os Direitos Humanos, dentre eles o Direito à Segurança pessoal, tem um impacto deveras negativo.

Isso porque, no caso específico do direito à segurança pessoal no âmbito do Mercosul, o recurso (muitas vezes falacioso) à defesa da soberania, vista a partir do conceito arcaico de Estado, acaba por criar obstáculos para que tal direito se desenvolva e seja observado de forma satisfatória. Cumpre, assim, pesquisar a existência de alternativas ao modelo ultrapassado de soberania nacional hermética que, ao que parece e conforme consta nos relatórios da CIDH e do Mercosul, é incapaz de debelar as violações do direito à segurança cidadã, mormente nas regiões de fronteira.

Uma alternativa possível e viável seria a mudança de paradigma constitucional nos países do Mercosul, a partir da migração do modelo clássico de constitucionalismo, embasado 
na soberania nacional exacerbada, para o que se denomina de "Estado Constitucional Cooperativo", enunciado por Peter Häberle, nos seguintes termos:

Estado Constitucional Cooperativo é o Estado que justamente encontra a sua identidade também no Direito Internacional, no entrelaçamento das relações internacionais e supranacionais, na percepção da cooperação e responsabilidade internacional, assim como no campo da solidariedade. Ele corresponde, com isso, à necessidade internacional de políticas de paz.

O Estado Constitucional Cooperativo é a resposta interna do Estado Constitucional ocidental livre e democrático à mudança no Direito Internacional e ao seu desafio que levou a formas de cooperação.

O Estado Constitucional aberto somente pode existir, a longo prazo, como Estado cooperativo, ou não é um Estado 'Constitucional'. Abertura para fora se chama cooperação.

Hoje o Estado Constitucional e o Direito Internacional transformam-se em conjunto. O Direito Constitucional não começa onde cessa o Direito Internacional. Também é válido o contrário, ou seja, o Direito Internacional não termina onde começa o Direito Constitucional.

Os cruzamentos e as ações recíprocas são por demais intensivas para que se dê a esta forma externa de complementariedade uma ideia exata. O resultado é o 'Direito comum de cooperação'.

O Estado Constitucional Cooperativo não conhece alternativas de uma 'primazia' do Direito Constitucional ou do Direito Internacional; ele considera tão seriamente o observado efeito recíproco entre as relações externas ou Direito Internacional, e a ordem constitucional interna (nacional), que partes do Direito Internacional e do direito constitucional interno crescem juntas num todo. (HÄBERLE, 2007, p.4 e 10)

Analisando-se os problemas enumerados nesse trabalho, decorrentes da violação do direito à segurança cidadã nas regiões de fronteira do Mercosul, a mudança para o paradigma acima proposto poderia ser objeto de ponderação entre os países componentes do bloco sul-americano, ainda que inicialmente esta mudança se opere somente em relação a alguns pontos sensíveis ao problema da segurança cidadã, para, depois, expandir-se às demais áreas, principalmente àquelas relacionadas à observância e preservação dos Direitos Humanos.

Outra opção igualmente viável, e que poderia ser utilizada singularmente ou em conjunto com a tratada anteriormente, é a do Transconstitucionalismo, idealizada por Marcelo Neves, que vislumbra a existência de problemas comuns a duas ou mais nações:

O fato é que, mais recentemente, com a maior integração da sociedade mundial, esses problemas tornaram-se insuscetíveis de serem tratados por uma única ordem jurídica estatal noâmbito do respectivo território. Cada vez mais, problemas de direitos humanos ou fundamentais e de controle e limitação de poder tornam-se concomitantemente relevantes para mais de uma ordem jurídica, muitas vezes não estatais, que são chamadas ou instadas a oferecer respostas para a sua solução. Isso implica uma relação transversal permanente entre ordens jurídicas em torno de problemas constitucionais comuns. $\mathrm{O}$ direito constitucional, nesse sentido, embora tenha a sua base originária no Estado, dele se emancipa, não precisamente porque surgiu uma multidão de novas Constituições, mas sim tendo em vista que outras ordens jurídicas estão envolvidas diretamente na solução dos problemas constitucionais básicos, prevalecendo, em muitos casos, contra a orientação das respectivas ordens estatais. 


\begin{abstract}
Em face dessa situação, introduzo o conceito de transconstitucionalismo. Não se trata, portanto, de constitucionalismo internacional, transnacional, supranacional, estatal ou local. O conceito aponta justamente para o desenvolvimento de problemas jurídicos que perpassam os diversos tipos de ordens jurídicas. Um problema transconstitucional implica uma questão que poderá envolver tribunais estatais, internacionais, supranacionais e transnacionais (arbitrais), assim como instituições jurídicas locais nativas, na busca de sua solução. (NEVES, 2018, p. XXI)
\end{abstract}

Em outra passagem, o autor, apresentando seu trabalho, destaca a problemática envolvendo mais de duas ordens jurídicas, e a inter-relaciona com questões de direitos humanos:

[...] passarei a considerar o transconstitucionalismo não apenas entre duas ordens jurídicas, da mesma espécie ou de tipos diferentes, mas também entre uma pluralidade de ordens jurídicas em um sistema mundial de níveis múltiplos, caracterizado por hierarquias entrelaçadas. Também como base em casos jurídicos de natureza constitucional, serão discutidas situações em que diversas ordens estão envolvidas, simultaneamente, na solução de um caso. A esse respeito, terá relevância particular o transconstitucionalismo pluridimensional dos direitos humanos, envolvendo uma multiplicidade de ordens jurídicas. (NEVES, 2018, p. 29).

Com a aplicação paradigmática de um dos conceitos apresentados, ou de ambos harmonicamente, a problemática referente à efetividade da segurança cidadã nos países do Mercosul muito provavelmente seria melhor equacionada e tratada, dentro de uma perspectiva de garantia dos direitos humanos que, há muito, são negados às populações fronteiriças das nações componentes do bloco.

\title{
5 PROPOSIÇÕES INTEGRATIVAS PARA O PROBLEMA DA VIOLÊNCIA CONTRA AS POPULAÇÕES FRONTEIRIÇAS DO MERCOSUL
}

É verdade que o Mercosul, por iniciativas do Instituto de Políticas Públicas em Direitos Humanos do Mercosul (IPPDH) e de outros órgãos, vem debatendo a problemática, com a realização de reuniões de autoridades, painéis, seminários e relatórios. Mas também é verdade que por diversas razões o direito à segurança cidadã é pouco franqueado às populações do bloco latino-americano, mormente as que habitam as regiões de fronteira.

Daí advém a necessidade premente de se criar um modelo de gestão da segurança cidadã com base nos paradigmas de cooperação apresentados no item antecedente deste trabalho, quais sejam, o Estado Constitucional Cooperativo e/ou o Transconstitucionalismo.

Um modelo de cooperação internacional possível seria um em que cada país do Mercosul compartilharia parcialmente sua soberania em favor de uma organização (ou agência) internacional, composta por agentes de todos os países envolvidos que atuariam em conjunto, com objetivo a combater, de forma coordenada e efetiva, a problemática da prática de crimes transnacionais nas faixas de fronteira e, dessa forma, salvaguardar os direitos à segurança cidadã das populações fronteiriças e todos aqueles que lhe são consectários (direito à vida, à integridade física e psíquica, ao desenvolvimento, etc.).

A título de exemplo, essa organização (ou agência) transnacional proposta poderia comandar e coordenar ações de investigações policiais para coibir crimes transnacionais. Seria uma espécie de Polícia Especial, formada por agentes dos Estados membros do Mercosul, juntamente com os Ministérios Públicos de tais países, todos especializados na investigação dos delitos em questão, que poderiam transitar entre os países para proceder às investigações e aos procedimentos policiais e investigativos necessários. Ao mesmo tempo, Magistrados 
dos países do bloco sul-americano, atuando em nome da novel organização transnacional, previamente preparados e designados para servir a esse tipo de trabalho (em respeito, portanto, ao princípio do Juiz Natural), também atuariam juntamente com a Polícia Especial. Assim, em um determinado caso hipotético de investigação de um crime de tráfico de drogas internacional, um mandado de prisão poderia ser expedido por um Juiz brasileiro e cumprido no Paraguai pela Polícia Especial transfronteiriça, sendo que o agente policial responsável pela prisão do criminoso poderia ser de nacionalidade boliviana. Ter-se-ia, na hipótese, um exemplo de atuação de membros de pelo menos três países do Mercosul em um caso real de elucidação de fato criminoso.

Como não há no bloco documento(s) que tenha(m) referida amplitude, a questão seria objeto de normativa de lege ferenda, ou seja, a ser criada posteriormente, depois de discussões e ajustes detalhados e muito bem alinhavados entre os países envolvidos. Nesse sentido, as questões legais necessárias para a operacionalização da proposta passariam pela elaboração de Tratados e outros instrumentos de Direito Internacional debatidos, confeccionados e assinados pelos países integrantes do Mercosul, num esforço conjunto para minorar os efeitos do crime organizado que atua principalmente nas regiões de fronteira das nações sul-americanas.

Os tratados supramencionados estabelecer, também, que eventuais abusos perpetrados pelos agentes constituídos para atuarem em nome da referida agência transnacional, seriam objeto de investigação e processo perante alguma comissão integrante do Mercosul ou, ainda, perante a Comissão Interamericana de Direitos Humanos e, eventualmente, de punição perante a Corte Interamericana de Direitos Humanos, se for o caso. A Corte, nesse caso, puniria a organização supranacional formada no âmbito do Mercosul para operacionalização do direito à segurança cidadã no bloco, que, na hipótese, teria eventualmente permitido que Direitos Humanos fossem violados por organização criada a pretexto de combater a violação de tais direitos. Na própria criação da organização supranacional já haveria um sistema de freios e contrapesos para controlar e fiscalizar suas atividades.

\section{CONSIDERAÇÕES FINAIS}

No desenvolvimento do presente trabalho abordou-se a problemática da segurança das populações fronteiriças do Mercosul. O enfoque emprestado à questão foi o da efetividade do Direito à Segurança Pessoal que se deve conferir ao indivíduo, numa perspectiva de direitos humanos, como forma de garantia do direito à vida e à integridade física, moral e/ou psíquica e, ainda, do direito ao desenvolvimento, o que se contrapõe à notória atuação de organizações criminosas internacionais principalmente na região de fronteiras, com atividades ligadas ao narcotráfico, tráfico de armas, contrabando, dentre outras.

Para tanto, pesquisou-se sobre os conteúdos jurídicos do Direito à Segurança Pessoal no âmbito da OEA e do Mercosul, ocasião em que foi possível constatar-se que a temática tem espaço cada vez mais crescente e preocupante, fato que levou as organizações supracitadas a se reunirem e a produzirem documentos, com vistas a traçar um panorama do quadro de violência do continente e a expedir recomendações aos Estados membros dos blocos sobre como atuar em relação aos problemas constatados.

Foi objeto de pesquisa, também, o contexto social das pessoas que habitam as fronteiras, sendo possível observar-se que a violência naquelas regiões, ocasionada pela prática excessiva de crimes transnacionais, afeta sobremaneira a vida cotidiana dessas pessoas. Tal conclusão se deu por análise de relatórios e outros documentos produzidos no âmbito dos órgãos da OEA, do Mercosul e de outras instituições, os quais apontam que, além de atentar contra a 
vida e integridade dos indivíduos, a crescente criminalidade transnacional também contribui para o subdesenvolvimento social, cultural e econômico das regiões de fronteira do Mercosul, com baixos índices de empregabilidade e de escolaridade, o que tem impacto direto e viola frontalmente o Direito ao Desenvolvimento dos indivíduos.

Como resposta à problemática constatada, sugeriu-se a implantação de instrumentos que visem a cooperação entre as nações integrantes do Mercosul, por meio de conceitos tirados do Estado Constitucional Cooperativo e/ou do Transconstitucionalismo, e a instituição de organização (ou agência) supranacional, constituída por agentes especializados na prevenção e repressão às condutas típicas dos criminosos transnacionais que atuam nas regiões de fronteira, como forma racional de resposta à situação, tendente a efetivar, de forma satisfatória, o direito à segurança cidadã e, consequentemente, o desenvolvimento no âmbito sub-regional.

Constatou-se que, pelos anos de construção de uma Teoria Geral do Estado arcaica nos países sul-americanos, que vislumbra a soberania como valor absoluto e incontrastável interna ou externamente, poderá haver alguns entraves e empecilhos para a integração e cooperação efetiva do bloco latino-americano. Em contraposição, restou confirmada a premente necessidade de atuação dos membros do Mercosul no sentido de dialogar e cooperar de forma mútua, coordenada e integrada, haja vista que o que está em jogo é a preservação dos direitos humanos à vida, à integridade pessoal e ao desenvolvimento, dentre outros, que certamente só podem ser salvaguardados por um funcional e efetivo sistema transnacional que privilegie a segurança cidadã, como preconizado pelas Organizações Internacionais das Américas.

\section{REFERÊNCIAS}

AGUILERA URQUIZA, Antonio Hilario; RIBEIRO, Leonardo Cavallini. Paradoxos da Globalização, Fronteiras Culturais e Direitos Humanos. Revista Direito UFMS, Campo Grande, volume 3, número 2, p. 241/26o, 2017.

ALVES, José Augusto Lindgren. Os direitos humanos como tema global. Perspectiva: São Paulo, 2011.

BOBBIO, Norberto. A Era dos Direitos. Elsevier: Rio de Janeiro, 2004.

BONAVIDES, Paulo. Teoria Geral do Estado. Malheiros Editores: São Paulo, 2012.

CARVALHO, Luciani Coimbra de; ARAUJO, Ana Paula Correia de; CONCEIÇÃO, Orsolina Fernandes da. A Escola no Brasil para brasileiros e bolivianos. In: AGUILERA URQUIZA, Antonio Hilario. Fronteira dos Direitos Humanos - Direitos Humanos nas Fronteiras. Ed. UFMS: Campo Grande, 2016.

CERVINI, Raúl; TAVARES, Juarez. Princípios de Cooperação Judicial Penal Internacional no Protocolo do Mercosul. Editora Revista dos Tribunais: São Paulo, 2000.

COMISSÃO INTERAMERICANA DE DIREITOS HUMANOS. CIDH. Relatório sobre segurança cidadã e direitos humanos. OEA, 2010. Disponível em: <https://cidh.oas.org/pdf\%2ofiles/ SEGURIDAD\%20CIUDADANA\%202009\%2oPORT.pdf> Acesso em: 04 jul. 2018. 
COMPARATO, Fábio Konder. A Afirmação Histórica dos Direitos Humanos. Saraiva: São Paulo, 2015.

DALLARI, Dalmo de Abreu. Elementos de Teoria Geral do Estado. Saraiva: São Paulo, 2009.

HÄBERLE, Peter. Estado Constitucional Cooperativo. Tradução: Marcos Augusto Maliska e Elisete Antoniuk. Renovar: Rio de Janeiro, 2007.

KELSEN, Hans. Teoria Geral do Direito e do Estado. Tradução: Luís Carlos Borges. Martins Fontes: São Paulo, 2000.

LARA ALEGRE, Ana Isabel Burke de. Globalização vs. Segurança: o papel das fronteiras. In: ANJOS FILHO, Robério Nunes dos. Globalização, justiça e segurança humana: capacitação para a compreensão dos grandes desafios do século XXI. Ed. Escola Superior do Ministério Público da União - Série pós-graduação: Brasília, 2011.

LESSA, Luiz Fernando Voss Chagas. AAssistência Direta ea Persecução Penal Transnacional pelo Ministério Público Brasileiro. Rio de Janeiro, 2009. $353 \mathrm{f}$. Tese (Doutorado em Direito) - Departamento de Direito, Pontifícia Universidade Católica do Rio de Janeiro, Rio de Janeiro, 2009 .

MENDES, Gilmar Ferreira; BRANCO, Paulo Gustavo Gonet. Curso de Direito Constitucional. Saraiva: São Paulo, 2017.

MERCOSUL. Produção e gestão da informação e do conhecimento no campo da segurança cidadã: os casos da Argentina, Brasil, Paraguai e Uruguai. Instituto de Políticas Públicas em Direitos Humanos (IPPDH). 2012. Disponível em: <http://www.ippdh.mercosur.int/ptbr/producao-e-gestao-da-informacao-e-do-conhecimento-no-campo-da-seguranca-cidadaos-casos-da-argentina-brasil-paraguai-e-uruguai/>. Acesso em: 04 jul. 2018.

MEZZAROBA, Orides; MONTEIRO, Cláudia Servilho. Manual de Metodologia da Pesquisa no Direito. Saraiva: São Paulo, 2017.

MIRANDA, Jorge. O Estado Constitucional Cooperativo e o Jus-Universalismo da Constituição Portuguesa. Revista do Ministério Público do Estado do Rio de Janeiro - 50 anos, Rio de Janeiro, n. 63, p. 99-111, 2017.

NEVES, Marcelo. Transconstitucionalismo. Editora WMF Martins Fontes: São Paulo, 2009.

Operações de Segurança nas Áreas de Fronteira. Instituto de Desenvolvimento Econômico e Social de Fronteiras. IDESF, 2016. Disponível em: <http://www.idesf.org.br/wp-content/ uploads/2016/o8/Opera $\% \mathrm{C}_{3} \% \mathrm{~A}_{7} \% \mathrm{C}_{3} \% \mathrm{~B}_{5}$ es-de-seguran ${ }_{0} \mathrm{C}_{3} \% \mathrm{~A}_{7}$ a-nas- $\% \mathrm{C}_{3} \% A 1 r e a s-d e-$ fronteira.pdf $>$. Acesso em: 30 jul. 2018.

ORGANIZAÇÃO DAS NAÇÕES UNIDAS. Declaração Universal dos Direitos Humanos-1948. ONUBR. Disponível em: <http://www.onu.org.br/img/2014/o9/DUDH.pdf>. Acesso em: 04 jul. 2018. 
. Declaração sobre o Direito ao Desenvolvimento- 1986. Biblioteca Virtual de Direitos

Humanos. USP. Disponível em: <http://www.direitoshumanos.usp.br/index.php/Direito-aoDesenvolvimento/declaracao-sobre-o-direito-ao-desenvolvimento.html>. Acesso em: 15 jul. 2018.

PIOVESAN, Flávia. Direitos Humanos e o Direito Constitucional Internacional. Saraiva: São Paulo, 2006.

SÁTIRO, Guadalupe Souza; MARQUES, Verônica Teixeira; OLIVEIRA, Liziane Paixão Silva. O Reconhecimento Jurídico do Direito ao Desenvolvimento como um Direito Humano e sua Proteção Internacional e Constitucional. Revista Direito e Desenvolvimento, João Pessoa, v. 7, n. 1, p. 170-189, 2016.

SEN, Amartya. Desenvolvimento como Liberdade. Tradução: Laura Teixeira Motta. Companhia das Letras: São Paulo, 2010.

SILVA, Virgílio Afonso da. Interpretação Constitucional. Malheiros: São Paulo, 2010.

SILVEIRA, Vladmir Oliveira da; CONTIPELLI, Ernani. Direitos Humanos Econômicos na Perspectiva da Solidariedade: Desenvolvimento Integral. Anais... Salvador, 2008. Disponível em <http://www.publicadireito.com.br/conpedi/manaus/arquivos/anais/salvador/ernani_ contipelli.pdf $>$. Acesso em: 04 jul. 2018.

SILVEIRA, Vladmir Oliveira da; MEYER-PFLUG, Samantha Ribeiro. Tratados de Direitos Humanos e a evolução jurisprudencial do Supremo Tribunal Federal. In: BAEZ, Narciso Leandro Xavier. A Problemática dos Direitos Humanos Fundamentais na América Latina e na Europa - Desafios materiais e eficácias. Ed. Unesco: Joaçaba, 2012.

NASPOLINI, Samyra Haydêe Dal Farra. O Sistema Interamericano de Direitos Humanos e sua relação com os países da América do Sul. In: IV SEMINÁRIO LATINOAMERICANO DE DIREITOS HUMANOS. Anais... Ceará, 2013.

ROCASOLANO, Maria Mendez. Direitos Humanos: conceitos, significados e funções. Saraiva: São Paulo, 2010.

TORRADO, Jesús Lima. Globalización y derechos humanos. Anuário de filosofía del derecho, n. 17, 200o. Disponível em: <https://dialnet.unirioja.es/servlet/articulo?codigo=14 2424>. Acesso em: 26 jun. 2018. 